\title{
A simplified technique for pulmonary artery aneurysm repair in a lung transplant recipient with right ventricular outflow tract obstruction
}

\author{
Giorgio Zanotti, MD, ${ }^{a}$ Matthew G. Hartwig, MD, ${ }^{\mathrm{b}}$ and R. Duane Davis, MD, ${ }^{\mathrm{b}}$ Durham, NC
}

Aneurysm of the pulmonary artery (PA) poses a technical dilemma at the time of lung transplant. Isolated reconstruction of the PA and heart-lung transplantation have been used. ${ }^{1-3}$ However, such options are often not appropriate in the face of right ventricular outflow tract (RVOT) obstruction, recoverable recipient right ventricular function, or unsuitable heart donors.

For the first time, we describe an en bloc RVOT-isolated lung transplant for a lung transplant recipient with congenital pulmonary valve disease and aneurysm of the PA. The rationale of this technique is to simplify repair of complex anatomy and to increase donor organ use.

\section{CLINICAL SUMMARY}

A 62-year-old man with a history of idiopathic pulmonary fibrosis, congenital pulmonic valve stenosis, and aneurysmal main and left PAs was placed on the waiting list for single left lung transplant at our institution because of se-

From the Divisions of General Surgery ${ }^{\mathrm{a}}$ and Cardiothoracic Surgery, ${ }^{\mathrm{b}}$ Department of Surgery, Duke University Medical Center, Durham, NC.

Disclosures: Authors have nothing to disclose with regard to commercial support.

Received for publication May 31, 2012; revisions received July 31, 2012; accepted for publication Aug 7, 2012; available ahead of print Sept 3, 2012.

Address for reprints: Giorgio Zanotti, MD, Duke University Medical Center, Duke South-White Zone, Box 3443, Durham, NC 27710 (E-mail: giorgio.zanotti@ dm.duke.edu).

J Thorac Cardiovasc Surg 2013;145:295-6 $0022-5223 / \$ 36.00$

Copyright (C) 2013 by The American Association for Thoracic Surgery http://dx.doi.org/10.1016/j.jtcvs.2012.08.027 vere pulmonary fibrosis. Preoperative cardiac magnetic resonance imaging demonstrated a main PA diameter of $4.9 \times 4.3 \mathrm{~cm}$, a left PA diameter of $5.6 \times 5.4 \mathrm{~cm}$, and a right PA diameter of $2.3 \times 2.2 \mathrm{~cm}$ (Figure 1). The pulmonic valve was dystrophic with a transvalvular peak gradient of $30 \mathrm{~mm}$ $\mathrm{Hg}$. Biventricular systolic function was preserved and right heart catheterization revealed normal PA pressures. Pulmonary function testing revealed a total lung capacity of $42 \%$ of predicted, a room air $\mathrm{PaO}_{2}$ of $48 \mathrm{~mm} \mathrm{Hg}$, and a diffusion capacity of $26 \%$ of predicted. Lung ventilation-perfusion scan showed a differential perfusion of $47 \%$ and $53 \%$ to the left and right lungs, respectively. When donor lungs became available, the patient underwent en bloc RVOT-isolated left lung transplant. The donor heart was not procured owing to depressed systolic function. Both lungs were assigned to our center.

The chest was entered via a median sternotomy, cardiopulmonary bypass was instituted via aorta-bicaval cannulation, and the operation was performed without cardiac arrest. The PAs were mobilized intrapericardially and extrapericardially and the left lung was removed. The donor lung was placed in the chest cavity and the donor bronchus was intussuscepted into the recipient's using a running 4-0 Maxon polyglycolic acid suture (United States Surgical Corporation, Norwalk, Conn). The left atrial cuff was then anastomosed using a running 5-0 polypropylene suture. The recipient's main PA was opened and all aneurysmal PA tissue, the pulmonary root, and part of the recipient RVOT were resected. The right ventricle was

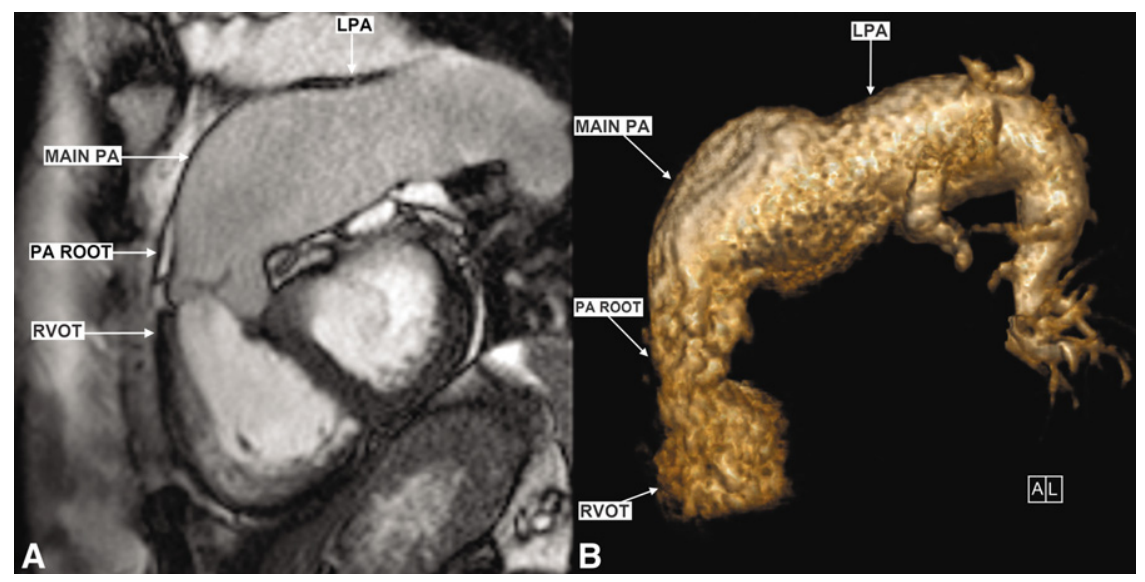

FIGURE 1. A and B, Preoperative cardiac magnetic resonance imaging. B, The right pulmonary artery is obscured by the left pulmonary artery. $L P A$, Left pulmonary artery; $P A$, pulmonary artery; RVOT, right ventricular outflow tract. 


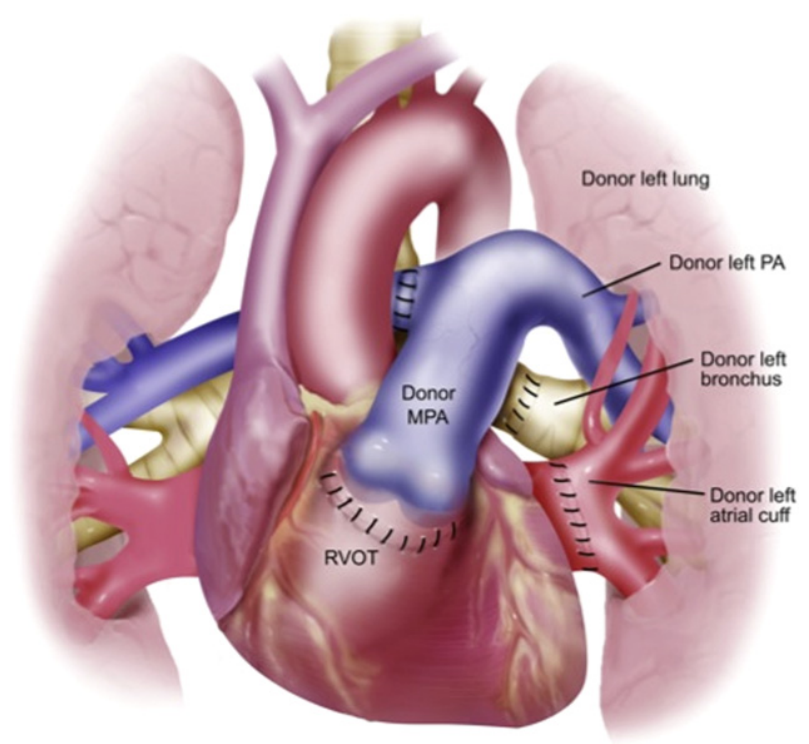

FIGURE 2. Completed RVOT, right pulmonary artery, left main stem bronchus, and left atrial anastomoses. RVOT, Right ventricular outflow tract; $P A$, pulmonary artery; $M P A$, main pulmonary artery.

vented to allow RVOT reconstruction on a beating heart. The donor RVOT myocardium was anastomosed to the recipient RVOT myocardium with a running 4-0 polypropylene suture in a double-layer fashion. The recipient's right PA was then anastomosed to the donor main PA in an end-to-side fashion using a running 6-0 polypropylene suture (Figure 2).

The patient was extubated on postoperative day 1 and discharged home on postoperative day 9 on room air. His only immediate postoperative complication was new-onset atrial fibrillation successfully treated with amiodarone. Six months postoperatively, transthoracic echocardiogram showed normal biventricular size and systolic function. Pulmonary valve shape, mobility, and transvalvular gradients were normal.

\section{SUMMARY}

Aneurysm of the PA in the setting of lung transplantation represents a technical conundrum. Aneurysmorrhaphy with reconstruction of the PA has been previously described. $^{1,2}$ However, it is a complex procedure, may necessitate the use of prosthetic material, and requires the presence of an anatomically and functionally intact PA root. Furthermore, heart-lung transplantation is indicated only in recipients of young age and with unrecoverable biventricular function. Pulmonary artery cryopreserved allografts are used for the repair of RVOT obstruction and have a 10-year survival of $50 \%$ to $90 \%{ }^{4}$; however, in contrast to fresh heart valves from transplanted hearts, they show severe degeneration early after implantation with loss of cell function. Most important, fresh heart valves from transplanted hearts appear to be unaffected by rejection. ${ }^{4}$ In our case, the donor heart was not being procured and the entire RVOT was available for harvest. Twenty-eight percent of multiorgan donors do not meet criteria for heart donation ${ }^{5}$ and yet the RVOT may still be safely transplanted, thereby providing a possible alternative to the issue of heart-lung bloc availability.

The key elements to guide PA reconstruction at the time of lung transplant are as follows: recipient age, cardiac function, integrity of the pulmonic valve, donor organ availability, and available length of donor PA or aorta for use as an interposition graft.

In conclusion, en bloc donor RVOT-lung allotransplantation is a technically efficient and effective procedure that provided good functional results in our patient and should therefore be considered as a surgical option in a lung transplant recipient with RVOT obstruction, PA aneurysm, and recoverable right ventricular function should the donor heart be unsuitable for transplantation.

We thank Mrs Brandi D. Tuttle, Duke University Medical Center Library, for her assistance with figure editing.

\section{References}

1. Force SD, Lau CL, Moazami N, Trulock EP, Patterson GA. Bilateral lung transplantation and pulmonary artery reconstruction in a patient with chronic obstructive pulmonary disease and a giant pulmonary artery aneurysm. $J$ Thorac Cardiovasc Surg. 2003;126:864-6.

2. Wekerle T, Klepetko W, Shahrokh T, Birsan T. Lung transplantation for primary pulmonary hypertension and giant pulmonary artery aneurysm. Ann Thorac Surg. 1998;65:825-7.

3. Wuyts WA, Herijgers P, Budts W, De Wever W, Delcroix M. Extensive dissection of the pulmonary artery treated with combined heart-lung transplantation. $J$ Thorac Cardiovasc Surg. 2006;132:205-6.

4. Mitchell RN, Jonas RA, Schoen FJ. Pathology of explanted cryopreserved allograft heart valves: comparison with aortic valves from orthotopic heart transplants. J Thorac Cardiovasc Surg. 1998;115:118-27.

5. OPTN/SRTR Data: SRTR \& OPTN Annual Report, 2010. 